Original article

\title{
Does body mass index influence cognitive functions among young medical students?
}

\author{
Yogitha Khade $^{\text {a }}$, A.V. Siva Kumar ${ }^{\text {b, }}$, K.N. Maruthy ${ }^{\text {b }}$, P. Sasikala ${ }^{\mathrm{b}}$ \\ ${ }^{a}$ Dept. of Physiology, Dr. Patnam Mahender Reddy Institute of Medical Sciences, Rangareddy, Telangana, India \\ ${ }^{\mathrm{b}}$ Dept. of Physiology, Narayana Medical College and Hospital, Nellore, Andhra Pradesh, India
}

\section{A R T I C L E I N F O}

\section{Keywords:}

Overweight

Obesity

Mini-mental state examination

Mild cognitive impairment

\begin{abstract}
A B S T R A C T
Background: Cognitive abilities are essential for young medical students to acquire the knowledge and same to be executed in clinical practice. There are a wide variety of risk factors that can lead to cognitive impairment and dementia in their early adolescence.

Objective: The present study was proposed to find out the extent of cognitive impairment and its association with body mass index among young medical students.

Materials \& methods: It was a cross-sectional study undertaken in 225 medical students, both male and female, aged between 18 and 20 years. Following the calculation of BMI, all individuals were divided into four groups. Later, the cognitive processes were examined on a single occasion using the Mini-Mental State Examination (MMSE).

Results: There was a significant link between systolic blood pressure (SBP), diastolic blood pressure (DBP), weight, and BMI in different groups. Similarly, significant values $(\mathrm{p}=0.04)$ were found among different groups in respect to gender, with obese females $(41.1 \%)$ having a higher percentage distribution than males. The link of BMI with cognitive scores was found to be significantly higher (p0.01) among distinct groups.

Conclusion: According to the findings of this study, a greater BMI may raise the likelihood of cognitive impairment in young students. Our findings imply that students with a high BMI may benefit from weight management.
\end{abstract}

\section{Background}

Cognition is an imperative characteristic feature that represents the ability of an individual to obtain information and thus knowledge, using constant memory, attention, and language skills. There are a wide variety of factors that tends to cause cognitive impairment like age, BMI, diabetes milletus, hypertension and hypothyroidism. Cognitive impairment is one of the common health issue which ranges from mild to severe in intensity and increases significantly with age (Senile cognitive impairment). ${ }^{1}$ The risk factors of cognitive impairment are hypertension, diabetes mellitus, and tobacco use often associated with degenerative forms of cognitive impairment. ${ }^{2}$ These may root cerebral microvascular changes, with hypo perfusion; demyelization. Adolescence is a stage of rapid growth that necessitates a well-balanced diet due to increased activity and the progress of somatic and cognitive skills. ${ }^{3}$ According to neuropsychology, adequate nutrition along with physical activity is essential for cerbro-cortical development, ideal learning, and academic achievements. ${ }^{4}$ A significant shift in family lifestyles, including eating practices, physical inactivity, sedentary lifestyle, and stress due to the academic burden of studies has an impact to cause overweight in adolescents. ${ }^{5}$ Obesity is a classical non-communicable condition characterized by excess weight gain which has a significant destructive effect on quality of life. Diet, physical activity, global development, genetic liability, medications, financial strategies and endocrine disorders, are key factors that contribute to obesity for an individual or at environmental level. ${ }^{6,7}$ Obesity has an immense effect on all working systems including cognitive impairment. ${ }^{8,9}$ The prevalence of obesity is rising in an alarming state and the associated manifestations are serious among young adults. Globally overweight and obesity ranks fifth as leading cause of deaths worldwide. Obesity prevalence has nearly doubled between 1980 and 2008. As per the Indian Council of Medical Research-India Diabetes study 2015, $11.8 \%-31.3 \%$ adults are obese, $16.9 \%-36.3 \%$, are suffering from central obesity. In India Kerala female's ranks second among obesity compared

\footnotetext{
* Corresponding author. Department Of Physiology, Narayana Medical College, Nellore, 524003, India.

E-mail addresses: dryogitakhade@gmail.com (Y. Khade), reddy.sivakumar5@gmail.com (A.V.S. Kumar), dr.maruthy@gmail.com (K.N. Maruthy), drsasisatish@ gmail.com (P. Sasikala).
} 
to other states. ${ }^{10}$ Medical students are also not spared despite awareness of obesity-associated consequences. Apart from other non-communicable diseases, evaluation of cognitive impairment is obligatory, as this population is essential to anticipate and diagnose the clinical conditions in routine clinical postings, which depends on their cognitive skills. ${ }^{11}$ Body Mass Index (BMI) is a simple, low-cost variable that determines the health status of an individual. ${ }^{12,13}$ There is paucity in the literature on the association of BMI and cognitive tasks among young medical students, especially in the Indian population. Therefore, the contemporary study was envisioned to find out the extent of cognitive impairment and its association with body mass index among young medical students.

\section{Methodology}

A Cross-sectional study was carried out involving undergraduate medical students (male and females) aged between 18-20years. The study protocol was pre-approved by the Institutional ethical committee. Apparent healthy medical students were recruited using a simple random sampling technique from the host institute. The student with any psychiatric illness or under any antidepressant medications and a history of sleep abnormalities were excluded from the study. All participants were updated and intimated about study design, voluntarily registered and the informed consent form was appropriately obtained from all the participants earlier to their enrolment in the study as per the Declaration of Helsinki guidelines.

\subsection{Categorization of participants}

Total 225 undergraduate medical students from the first and second semesters were recruited for the study. Males (84) and females (141) were interviewed and demographics were obtained. Socio-demographic profiles and Anthropometric data (Name, Age, Gender, Height, and Weight) were collected. Each participant's height and weight were estimated using a digital weight machine and a wall meter, and BMI was calculated using Quetelet's Index. Based on the BMI, the study population was categorized into four groups according to standard criteria as follows Group A: Underweight $(\mathrm{n}=24), \mathrm{BMI}=(<18.5 \mathrm{~kg} / \mathrm{m} 2)$, Group B: Normal weight $(\mathrm{n}=63), \mathrm{BMI}=(18.5-22.9 \mathrm{~kg} / \mathrm{m} 2)$, Group C: Overweight $(\mathrm{n}=66), \mathrm{BMI}=(23-24.9 \mathrm{~kg} / \mathrm{m} 2)$ and Group D: Obese $(\mathrm{n}=75)$, $\mathrm{BMI}=(\geq 25.0 \mathrm{~kg} / \mathrm{m} 2)$.

\subsection{Physiological parameters}

Pulse rate (beats/min), systolic (SBP), and diastolic blood pressures (DBP) were obtained in the right arm using digital blood pressure apparatus (Omron T-4). Mean arterial pressure was calculated by the formula, $\mathrm{MAP}=\mathrm{DBP}+1 \backslash 3 \mathrm{PP}$ (pulse pressure).

\subsection{Mini-mental state examination}

A self-administered and standardized 30 item Mini-Mental State Examination (MMSE) questionnaire was administered and confidentiality of the results was assured. Mini-Mental State Examination is a wellorganized and composed screening measure of cognitive functions used in most of the studies for evaluation of cognition. It is an objective assessment and abnormal scores of MMSE are suggestive of MCI. The questionnaire consists of 11 questions and it is a written examination scored on a scale of 1-30. As per the MMSE, the cut-off score of cognitive deficiency is education-specific: $17 / 18$ for illiteracy, $20 / 21$ for individuals with primary education level, and $24 / 25$ for people with higher than primary education level. A score of $<24$ out of 30 in the MMSE states abnormal cognitive functions in college -students. The subjects were assessed based on their mental ability and presence of mind. It covers the six key cognitive domains of verbal fluency, judgment, expressive language, visual construction, immediate and late free verbal recall, and clued verbal recall. ${ }^{14}$

\section{Statistical analysis}

Data sets were analyzed using Statistical Package for the Social Sciences (SPSS) version 11. Data obtained was expressed as mean and standard deviation. Data sets were checked for normal distribution. Measures of central tendency, dispersion, and chi-square tests. The Chisquare test was applied to assess the relationship between the two variables. Comparison of anthropometric and Physiological parameters between groups was done using one-way analysis of variance with post hoc analysis.

\section{Results}

All four groups were age-matched. Among 225 students $(62.7 \%$ females, $37.3 \%$ males), (24.9\%), belongs to $18 \mathrm{yrs}$, (52.4\%) 19 yrs and (22.6\%) belong to 20 yrs (22.6\%). Among these participants, $33.3 \%$ were obese, $29.3 \%$ overweight, $28 \%$ normal weight, and $9.3 \%$ underweight. As expected, systolic blood pressure, diastolic blood pressure, weight, BMI were statistically significant among the four groups as shown in (Table 1). Comparison between the groups was done by oneway ANOVA with post hoc analysis. There was a significant difference among gender and BMI was observed among all four groups (Table 2). A significant association was observed between BMI and cognitive scores among all four groups (Table 5). It was found that the cognition score obtained by the normal BMI group was higher than the score obtained by the remaining three groups. In addition, a lower score of cognitive functions was witnessed in obese individuals when equated with normal weight, especially in women. No significant changes were observed between age, gender, and cognitive scores (Tables 3 and 4).

\section{Discussion}

The present study was concentrated to find out the extent of cognitive impairment and its association with BMI in young medical students. We got significant differences in cognitive abilities among four groups especially reduced in overweight and obese medical students suggesting cognitive impairment. Physical and cognitive abilities are two types of abilities that humans possess where one is agitated, the other is affected as well. ${ }^{15}$ The impact of being overweight on cognition was under estimated which often goes undetected especially in medical fraternities. ${ }^{16}$ Young medical student's cognitive abilities should be adequate as they are in a phase to gain theoretical scientific knowledge,

Table 1

Comparison of Physiological and demographicvariables among four groups.

\begin{tabular}{|c|c|c|c|c|c|}
\hline Parameter & $\begin{array}{l}\text { Group A } \\
(\mathrm{n}=21)\end{array}$ & $\begin{array}{l}\text { Group B (n } \\
=63)\end{array}$ & $\begin{array}{l}\text { Group C } \\
(\mathrm{n}=66)\end{array}$ & $\begin{array}{l}\text { Group D (n } \\
=75)\end{array}$ & $p$ value \\
\hline Age (years) & $\begin{array}{l}18.71 \pm \\
0.64\end{array}$ & $\begin{array}{l}18.98 \pm \\
0.83\end{array}$ & $\begin{array}{l}18.86 \pm \\
0.69\end{array}$ & $\begin{array}{l}18.80 \pm \\
0.77\end{array}$ & 0.41 \\
\hline PR & $\begin{array}{l}86.5 \pm \\
10.2\end{array}$ & $\begin{array}{l}91.5 \pm \\
12.7\end{array}$ & $\begin{array}{l}86.6+ \\
12.70\end{array}$ & $\begin{array}{l}88.08 \pm \\
12.58\end{array}$ & 0.12 \\
\hline $\begin{array}{l}\text { SBP } \\
\quad(\mathrm{mmHg})\end{array}$ & $\begin{array}{l}109.4 \pm \\
12.6\end{array}$ & $116 . \pm 12$ & $\begin{array}{l}122.7 \pm \\
13.11\end{array}$ & $\begin{array}{l}124.77 \pm \\
12.95\end{array}$ & $<0.001 *$ \\
\hline $\begin{array}{l}\text { DBP } \\
\quad(\mathrm{mmHg})\end{array}$ & $\begin{array}{l}70.9 \pm \\
8.18\end{array}$ & $\begin{array}{l}75.7 \pm \\
7.5 \mathrm{~d}\end{array}$ & $\begin{array}{l}79.36 \pm \\
9.77\end{array}$ & $\begin{array}{l}82.8 \pm \\
9.06\end{array}$ & $<0.001 *$ \\
\hline $\begin{array}{l}\text { Height } \\
(\mathrm{cm})\end{array}$ & $\begin{array}{l}160.6 \pm \\
9.41\end{array}$ & $\begin{array}{l}163.26 \pm \\
9.14\end{array}$ & $\begin{array}{l}163.7 \pm \\
10.49\end{array}$ & $\begin{array}{l}160.7 \pm \\
8.51\end{array}$ & 0.19 \\
\hline $\begin{array}{l}\text { Weight } \\
\text { (Kg) }\end{array}$ & $\begin{array}{l}44.6 \pm \\
6.46\end{array}$ & $\begin{array}{l}54.5 \pm \\
6.53\end{array}$ & $\begin{array}{l}64.03 \pm \\
8.94\end{array}$ & $\begin{array}{l}74.35 \pm \\
10.5\end{array}$ & $<0.001 *$ \\
\hline $\begin{array}{l}\text { BMI }(\mathrm{kg} / \\
\left.\mathrm{m}^{2}\right)\end{array}$ & $\begin{array}{l}20.2 \pm \\
1.06\end{array}$ & $\begin{array}{l}24.32 \pm \\
2.98\end{array}$ & $\begin{array}{l}24.6 \pm \\
2.51\end{array}$ & $\begin{array}{l}26.8 \pm \\
4.18\end{array}$ & $<0.001 *$ \\
\hline
\end{tabular}

Data are presented as mean $\pm \mathrm{SD}$. *Indicates the level of significance, $P>0.05$ : Not significant; ${ }^{*} P<0$.05: Significant; ${ }^{* *} P<0.01$ : Highly significant; ${ }^{* * *} P<$ 0.001: Very highly significant; BMI: body mass index; PR: pulse rate; SBP: systolic blood pressure; DBP: Diastolic blood pressure. 
Table 2

Distribution of gender among different groups.

\begin{tabular}{|c|c|c|c|c|c|c|}
\hline \multirow[t]{2}{*}{ Gender } & \multicolumn{4}{|l|}{ BMI } & \multirow[b]{2}{*}{ Total } & \multirow{2}{*}{$\begin{array}{l}\mathrm{p}- \\
\text { value }\end{array}$} \\
\hline & $\begin{array}{l}\text { Group A } \\
(\mathrm{n}=21)\end{array}$ & $\begin{array}{l}\text { Group B } \\
(\mathrm{n}=63)\end{array}$ & $\begin{array}{l}\text { Group C } \\
(\mathrm{n}=66)\end{array}$ & $\begin{array}{l}\text { Group D } \\
(\mathrm{n}=75)\end{array}$ & & \\
\hline Female & $\begin{array}{l}19 \\
(13.5 \%)\end{array}$ & $\begin{array}{l}35 \\
(24.8 \%)\end{array}$ & $\begin{array}{l}29 \\
(20.6 \%)\end{array}$ & $\begin{array}{l}58 \\
(41.1 \%)\end{array}$ & 141 & 0.04 * \\
\hline Male & $2(2.4 \%)$ & $\begin{array}{l}19 \\
(22.9 \%)\end{array}$ & $\begin{array}{l}22 \\
(25.3 \%)\end{array}$ & $\begin{array}{l}41 \\
(49.4 \%)\end{array}$ & 84 & \\
\hline Total & $21(9.4 \%)$ & $\begin{array}{l}54 \\
(24.1 \%)\end{array}$ & $\begin{array}{l}51 \\
(22.3 \%)\end{array}$ & $\begin{array}{l}99 \\
(44.2 \%)\end{array}$ & 225 & \\
\hline
\end{tabular}

Chi-square test was used; Data are presented as frequency, percentages, and $p$ values.

Table 3

Association of age on cognitive function.

\begin{tabular}{llllll}
\hline \multirow{2}{*}{ Age (Years) } & \multicolumn{2}{l}{ Score } & & \\
\cline { 2 - 3 } & Normal & MCI & & Total & p-value \\
\hline 18 & $26(46.4 \%)$ & $30(53.6 \%)$ & 56 & $0.05^{*}$ \\
19 & $37(31.4 \%)$ & $81(68.6 \%)$ & & 118 & \\
20 & $14(26.0 \%)$ & $37(74.0 \%)$ & & 51 & \\
Total & $77(34.2 \%)$ & $148(65.8 \%)$ & 225 & \\
\hline
\end{tabular}

A Chi-square test was used; Data are presented as frequency, percentages, and $p$ values.

MCI: Mild cognitive impairment.

Table 4

Association of gender with MMSE scores.

\begin{tabular}{|c|c|c|c|c|}
\hline \multirow[t]{2}{*}{ Gender } & \multicolumn{2}{|l|}{ MMSE Score } & \multirow[t]{2}{*}{ MMSE Score } & \multirow[t]{2}{*}{$p$-value } \\
\hline & Normal & MCI & & \\
\hline Male & $32(38.1 \%)$ & $52(61.9 \%)$ & 84 & 0.384 \\
\hline Female & $45(31.9 \%)$ & $96(68.1 \%)$ & 141 & \\
\hline Total & $77(34.2 \%)$ & $14(65.8 \%) 8$ & 225 & \\
\hline
\end{tabular}

A Chi-square test was used; Data are presented as frequency, percentages, and $p$ values.

MCI: Mild cognitive impairment.

Table 5

Association of BMI with MMSE scores.

\begin{tabular}{llll}
\hline \multirow{2}{*}{ BMI } & \multicolumn{2}{l}{ MMSE Score } & \multirow{2}{*}{$p$-value } \\
\cline { 2 - 3 } & Normal & MCI & \\
\hline Underweight & $12(57.1 \%)$ & $9(42.9 \%)$ & $<0.001^{*}$ \\
Normal & $38(59.3 \%)$ & $25(40.7 \%)$ & \\
Overweight & $18(20.0 \%)$ & $52(80.0 \%)$ & \\
Obese & $18(23.2 \%)$ & $57(76.8 \%)$ & \\
Total & $86(34.4 \%)$ & $143(65.6 \%)$ & \\
\hline
\end{tabular}

A Chi-square test was used; Data are presented as frequency, percentages, and $p$ values.

MCI: Mild cognitive impairment.

demonstrable clinical case scenarios. They must acquire the decision-making skills which completely depend on cognitive functions. Acts of cognition, and not just transfer of information, are the heart of liberating education. As a result, medical students, who represent the healthcare system's future, should be monitored regularly to avoid dementia in the future. Increased BMI is a two-edged sword: while obesity is linked to a slew of non-communicable diseases, being underweight is also linked to a slew of illnesses, including decreased immunity, delayed puberty, osteoporosis, anemia, and psychological issues. ${ }^{17}$

The current study has shown that systolic and diastolic blood pressure was significantly allied with all four groups. The findings are corroborated with Tesfayeet al - 2021(18) where Both SBP and DBP tend to elevate with high $\mathrm{BMI}^{18}$ Due to increased sympathetic activity, endothelial dysfunction, and an increase in cytokines, BMI has been shown to have negative effects on blood pressure. Poor eating is common among medical students due to time management, as the majority of their time is devoted to academic responsibilities. Obesity and lifestyle-related disease are on the rise, as are chronic medical disorders as a result of sedentary lifestyles with decreased physical activity. The findings have shown a significant association between gender and BMI. A higher percentage of males $(49.4 \%)$ were found to be obese than females (41.1\%). Our findings are consistent with previous research, which found that males are more obese than females and that females have a higher percentage of underweight women. ${ }^{19}$ Previous research has found a link between junk food and BMI, which could explain the current study outcome. Females are more sensitive to their weight and their health than guys. Few studies, particularly in males, have attempted to explain variations in weight, height, and BMI as a result of heredity, environmental, and genetic predisposes. ${ }^{20} \mathrm{We}$ also discovered that the link between fat and cognitive function was gender-specific where females exhibited a larger percentage of cognitive impairment (68.1\%) than males $(61.9 \%)$ in the current study, while the differences were not statistically significant. The findings are comparable to those of Noh et al. (2019), who discovered a sex difference in the connection between obesity and cognitive function among older females, but not among older men. ${ }^{21}$ There haven't been any studies on gender differences in cognitive processes among young students. According to studies, changes in fat distribution may play a role in the sex-related relationship between obesity and cognitive abilities. Women have more peripheral fat depots (subcutaneous fat) than males, whereas men have more visceral fat. We discovered a substantial difference in cognitive functioning between those who were underweight, had a normal BMI, and those who were overweight or obese in this study. Our findings are consistent with those of Chauhan et al. (2020) who found that overweight or obesity had an impact on young adults' performance in various facets of cognitive functioning. ${ }^{22}$ A study conducted in the United Kingdom indicated that underweight people (BMI $20 \mathrm{~kg} / \mathrm{m} 2$ ) had a $34 \%$ higher risk of dementia than normal-weight people $(20-25 \mathrm{~kg} / \mathrm{m} 2)$, whereas $29 \%$ of very obese people (BMI $>40 \mathrm{~kg} / \mathrm{m} 2)$ had a decreased risk. ${ }^{23}$ A similar study on young school students recognized that the participants with high BMI revealed a significant decrease in cognitive functions as matched to the students with normal BMI. Results of the study support the hypothesis that attention, memory, and recognition, are affected by high BMI as observed in different studies. $^{24,25}$ In a comparative study of young students, researchers discovered that those with a high BMI showed a significant delay in cognitive abilities when compared to those with a normal BMI. The findings confirm the concept that high BMI affects attention, memory, and recognition, as seen in other investigations. ${ }^{26}$ Few studies agree with our findings that long-term obesity and long-term underweight are linked to poorer cognitive performance in late middle age which both were linked to lower MMSE scores and executive function. Few studies agree with our findings that long-term obesity and long-term underweight are both linked to poorer MMSE scores and executive function in late middle age. As a result, studies emphasize the need of assessing BMI throughout a student's life to determine the relationship between body weight and cognition as they get older. ${ }^{27}$ On the contrary, a Chinese cross-sectional study found no association between overweight and obesity, although subjects with central obesity were at risk for cognitive impairment. ${ }^{28}$ Higher BMI has been linked to chronic low-grade inflammation and increased production of pro-inflammatory cytokines in the past, which could help to mitigate the negative effects of dopaminergic driven cognitive abilities seen in obese and overweight people. ${ }^{29}$ Higher levels of leptin, a hormone found in body fat, have been linked to poor cognitive function and the CRP has been associated with worse cognitive performance in obese women. ${ }^{30} \mathrm{~A}$ wide range of credible methods leading to a distinct effect of overweight or obesity on 
cognition, including structural brain alterations, poor cerebral metabolism, increased leptin, and inflammation, may be proposed in future research. Unlike previous Asian research, which focused primarily on the effects of baseline adiposity on future cognitive function, our current study looked at the effects of BMI fluctuations on cognitive skills in early adulthood.

\section{Limitations}

There are certain limitations to the current study as it was a crosssectional study; a complete analysis of different factors other than physical behavioral aspects will alter the outcome over time. The BMI does not distinguish between lean and fat mass. A better analysis of the students' food habits, physical activities, and stress levels would give better results. More research is needed in the future to determine the best relationship between body weights and cognitive deterioration in youngsters.

IMPLICATIONS: As dementia is an upcoming hidden disease affecting old age individuals, we wanted to evaluate whether the roots are in adulthood. Obesity is the house for all diseases so would there be any role of BMI in relation to cognitive functions among young medical students. The study also evaluated the relation with gender differences among the group.

FUTURE PLANS: The study can be further elaborated involving large number of students with wider age range. Detailed family history of obesity, diabetes mellitus, hypertension, hypothyroidism and dementia would help to relate the genetic history with impaired cognitive functions. Also other tests can be applied apart from MMSE like reaction time, academic performance. Apart from BMI, body fat percentage, visceral fat can be recorded.

\section{Conclusion}

According to the findings of this study, both underweight and obese people have reduced cognitive skills than people with a normal BMI. We discovered that a higher percentage of males were fat and a higher percentage of females had poorer cognitive ratings. This underlines the importance of including physical activities in the curriculum for medical students to lower body weight and improve cognitive functioning, as well as obesity-related issues. Obesity, on its own, raises the chance of cognitive impairment later in life. The MMSE is a standardized, valid, and reliable cognitive screener that medical students can use to improve their performance.

\section{Funding}

It is a self-funding project and did not receive any financial assistance. However, basic amenities were provided by the Host Institute.

\section{Ethical considerations}

The study protocol was approved by Institutional Ethics Committee, NRI Medical College and Hospital, Vishakhapatnam.

\section{Declaration of competing interest}

The corresponding author declares on behalf of all authors that there is no potential conflict of interest to publish the article.

\section{Acknowledgement}

The authors of the current study would like to express their heartfelt gratitude towards the Management of NRI Medical College and Hospital, Vishakhapatnam for their constant encouragement during the study period. We are also thankful to the participants for their cooperation during data collection.

\section{References}

1 Whelan S, Murphy K, Barrett E, Krusche C, Santorelli A, Casey D. Factors affecting the acceptability of social robots by older adults including people with dementia or cognitive impairment: a literature review. International Journal of Social Robotics. 2018 Nov;10(5):643-668.

2 Gorelick PB, Scuteri A, Black SE, et al. Vascular contributions to cognitive impairment and dementia: a statement for healthcare professionals from the American Heart Association/American Stroke Association. Stroke. 2011 Sep;42(9): 2672-2713.

3 Hollis JL, Collins CE, DeClerck F, Chai LK, McColl K, Demaio AR. Defining healthy and sustainable diets for infants, children and adolescents. Global Food Secur. 2020 Dec 1;27:100401.

4 Donnelly JE, Hillman CH, Castelli D, et al. Physical activity, fitness, cognitive function, and academic achievement in children: a systematic review. Med Sci Sports Exerc. 2016 Jun;48(6):1197.

5 Panahi S, Tremblay A. Sedentariness and health: is sedentary behavior more than just physical inactivity? Front Publ Health. 2018 Sep 10;6:258.

6 Chooi YC, Ding C, Magkos F. The epidemiology of obesity. Metabolism. 2019 Mar 1; 92:6-10.

7 Hruby A, Hu FB. The epidemiology of obesity: a big picture. Pharmacoeconomics. $2015 \mathrm{Jul} ; 33(7): 673-689$.

8 Prickett C, Brennan L, Stolwyk R. Examining the relationship between obesity and cognitive function: a systematic literature review. Obes Res Clin Pract. 2015 Mar 1;9 (2):93-113.

9 Leigh SJ, Morris MJ. Diet, inflammation and the gut microbiome: mechanisms for obesity-associated cognitive impairment. Biochim Biophys Acta (BBA) - Mol Basis Dis. 2020 Jun 1;1866(6):165767.

10 Ahirwar R, Mondal PR. Prevalence of obesity in India: a systematic review. Diabet \& Metabol Syndr: Clin Res Rev. 2019 Jan 1;13(1):318-321.

11 Jackson JM, Skelton JA, Peters TR. Medical students' clinical reasoning during a simulated viral pandemic: evidence of cognitive integration and insights on novices' approach to diagnostic reasoning. Med Sci Educ. 2020 Jun;30(2):767-774.

12 Lear SA, Humphries KH, Kohli S, Birmingham CL. The use of BMI and waist circumference as surrogates of body fat differs by ethnicity. Obesity. 2007 Nov;15 (11):2817-2824.

13 Pi-Sunyer FX. Obesity: criteria and classification. Proc Nutr Soc. 2000 Nov;59(4): 505-509.

14 Cockrell JR, Folstein MF. Mini-mental state examination. Princip Pract Geriatr Psychiatr. 2002 Apr 15:140-141.

15 Cohen-Mansfield J, Libin A. Verbal and physical non-aggressive agitated behaviors in elderly persons with dementia: robustness of syndromes. J Psychiatr Res. 2005 May 1; 39(3):325-332.

16 Redelmeier DA, Dickinson VM. Determining whether a patient is feeling better: pitfalls from the science of human perception. J Gen Intern Med. 2011 Aug 1;26(8): 900-906.

17 King BC, Blom AM. Complement in metabolic disease: metaflammation and a twoedged sword. InSeminars in Immunopathology 2021 Jun 22 (pp. 1-13). (Springer Berlin Heidelberg).

18 Tesfaye F, Nawi NG, Van Minh H, et al. Association between body mass index and blood pressure across three populations in Africa and Asia. J Hum Hypertens. 2007 Jan;21(1):28-37.

$19 \mathrm{Hu} \mathrm{J}, \mathrm{Fu} \mathrm{H}$, Shen H, et al. Does underweight amplify the relationship between shortterm particulate matter exposure and blood pressure in children and adolescents: a large cross-sectional study in a metropolis of China. Environ Sci Pollut Control Ser. 2020 Dec;27(34):42449-42459.

20 Farshchi HR, Taylor MA, Macdonald IA. Beneficial metabolic effects of regular meal frequency on dietary thermogenesis, insulin sensitivity, and fasting lipid profiles in healthy obese women. Am J Clin Nutr. 2005 Jan 1;81(1):16-24.

21 Noh HM, Han J, Kim YJ, Jung JH, Roh YK, Song HJ. Sex differences in the relationship between cognitive impairment and overweight or obesity in late life: a 3-year prospective study. Medicine. 2019 Mar;98(9).

22 Chauhan S, Shah S, Shah S. Impact of body mass index on cognitive function among young adults. Physiother J Indian Assoc Physiother. 2019 Jan 1;13(1):43.

23 Horie NC, Serrao VT, Simon SS, et al. Cognitive effects of intentional weight loss in elderly obese individuals with mild cognitive impairment. J Clin Endocrinol Metabol. 2016 Mar 1;101(3):1104-1112.

24 Chang YK, Chu CH, Chen FT, Hung TM, Etnier JL. Combined effects of physical activity and obesity on cognitive function: independent, overlapping, moderator, and mediator models. Sports Med. 2017 Mar;47(3):449-468.

25 Srinag L, Maruthy KN, Kareem SK, Kumar AS, Kumar K, Gurja JP. Impact of overweight on cognition and psychomotor skills among children with overweight. Obes Med. 2020 Jun 1;18:100191.

26 Privitera GJ, McGrath HK, Windus BA, Doraiswamy PM. Eat now or later: self-control as an overlapping cognitive mechanism of depression and obesity. PLoS One. 2015 Mar 26;10(3), e0123136.

27 Yuan Y, Li J, Zhang N, et al. Body mass index and mild cognitive impairment among rural older adults in China: the moderating roles of gender and age. BMC Psychiatr. 2021 Dec;21(1), 1-1. 
28 Zhang T, Yan R, Chen Q, et al. Body mass index, waist-to-hip ratio and cognitive function among Chinese elderly: a cross-sectional study. BMJ Open. 2018 Oct 1;8 (10), e022055.

29 Kumar CK, Maruthy KN, Sasikala P, Gurja JP, Kumar AV, Kareem SK. Impact of chronic alcoholism on temporal cognition and coordination of motor activity. Int $J$ Physiol. 2018;6(4):124-127.
30 Atienza M, Ziontz J, Cantero JL. Low-grade inflammation in the relationship between sleep disruption, dysfunctional adiposity, and cognitive decline in aging. Sleep Med Rev. 2018 Dec 1;42:171-183. 